\title{
Educación sentimental, humorismo y nuevos modelos femeninos: Plaerdemavida (Tirant), Triola (Platir) $y$ otras doncellas confidentes en libros de caballerías ${ }^{1}$
}

\author{
Sentimental Education, Humour and New Female Models of Behaviour: \\ Plaerdemavida (Tirant), Triola (Platir) and other \\ Confidants in Spanish Romances of Chivalry
}

\author{
Federica Zoppi \\ (Universidad de Zaragoza)
}

\begin{abstract}
RESUMEN
En el presente artículo se analiza un estereotipo femenino de los libros de caballerías, el de las doncellas confidentes, desde la perspectiva de la función didáctica que desempeñan en el ámbito sentimental y erótico respecto a sus amigas. Enfocando algunas figuras concretas, como Plaerdemavida en el Tirant lo Blanch y Triola en el Platir, se considera el valor del humorismo en la asunción de un papel educativo que posibilita el establecimiento, por parte de estas mujeres, de un juego con el concepto de amor y de sexualidad. Dicho juego participa en la creación de un paradigma de conducta femenina que se escapa de las normas convencionales para abrazar también costumbres potencialmente transgresivas desde el punto de vista social.
\end{abstract}

\section{Palabras Clave}

Tirant lo Blanc, Platir, libros de caballerías, educación sentimental, erotismo, doncella confidente.

\begin{abstract}
This article explores a specific female stereotype from the chivalry books, the female confidante, friend and damsel of another young maiden; the main focus is the analysis of the didactic function performed by their interaction with these young ladies, especially in sentimental and erotic matters field with respect to their friends. Focusing on some specific characters, such as Plaerdemavida in Tirant lo Blanch and Triola in Platir, humor plays an important role in this educational purpose, since it establishes a game with traditional literary and social conventions on the concept of love and female sexuality and it allows a more free and transgressive take in the creation of a paradigm of female behavior.
\end{abstract}

\section{KEYWORDS}

Tirant lo Blanc, Platir, chivalry novels, sentimental education, eroticism, confidance.

1. Este trabajo se integra en un proyecto que ha recibido financiación del programa de investigación e innovación Horizon 2020 de la Unión Europea en virtud del acuerdo de subvención no 794868. 
Recibido: 01/06/2020

Aceptado: 30/07/2020

Los libros de caballerías se caracterizan por ser un género literario cuya asombrosa difusión se debe a la capacidad de alcanzar un público de lectores más amplio de lo que cualquier otro género había conseguido hacer anteriormente, incluyendo en particular un público femenino que se apasionó por esta forma de entretenimiento ${ }^{2}$, atraído tanto por los enredos amorosos, como por los combates y los asuntos bélicos, en los que se ve reflejada cierta estética del erotismo (Huizinga, 2010: 109). Efectivamente las figuras femeninas desempeñan una función imprescindible en los libros de caballerías, puesto que se configuran como auténtico motor de la acción al ser inspiradoras de la mayoría de las aventuras relatadas ${ }^{3}$ : el caballero socorre a doncellas en peligro, responde a peticiones de ayuda de doncellas, se lanza en aventuras para dar prueba de su valor a su amada, dedicándole sus éxitos y luchando para defender su hermosura, etc. Este papel central de la presencia femenina en el mundo caballeresco queda bien claro a partir de la Edad Media - «cuando se estableció la cavallería, entre las otras cosas que era tenudo a guardar el que se armava cavallero era una que a las mugeres guardase toda reverencia y honestad» (Cárcel de amor: 158)- hasta llegar al Quijote, donde el hidalgo «limpias, pues, sus armas, hecho del morrión celada, puesto nombre a su rocín y confirmándose a sí mismo, se dio a entender que no le faltaba otra cosa sino buscar una dama de quien enamorarse, porque el caballero andante sin amores era árbol sin hojas $y$ sin fruto y cuerpo sin alma» (46).

A pesar de esto, la figura femenina, en general, no deja de presentar rasgos de ambigüedad, que oscilan entre un polo positivo y uno negativo: por una parte, la dama idealizada del amor cortés, objeto de culto y de reverencia, que impulsa las aventuras del caballero y le permite emprender su camino de perfección, tanto social como religioso; por otra parte, la mujer como tentación, imagen seductora que lleva a la perdición. El ámbito expresivo es precisamente donde estas dos concepciones chocan de forma más evidente: la manifestación sensual y física del amor forma parte integral del amor cortés, aunque se oponga a la lógica cristiana de la protección de la virginidad, que conlleva, a su vez, un fundamental valor social. Se pueden, entonces, identificar algunos personajes femeninos que parecen encarnar este contraste, convirtiéndose en un modelo femenino innovador que se coloca en el cruce de tradiciones diferentes: la compenetración de rasgos potencialmente opuestos, sobre todo en el ámbito del erotismo femenino, parece pasar a través de una mirada humorística y que armoniza el contraste gracias a la risa. En este sentido, resultan especialmente interesantes algunas figuras de mujeres confidentes que asisten a la doncella protagonista en su experiencia amorosa, proporcionando consejos y recomendaciones de naturaleza sentimental, e incluso sexual, frente a la pérdida de razón causada por el amor; parece ser necesaria la presencia de una figura que contrarreste, a través del ejercicio de la discreción, los excesos de la pasión. Estos personajes proporcionan una preceptiva sentimental inscrita, en algunos casos,

2. Marín Pina (1991) analiza la condición de la mujer lectora, a partir de varios testimonios medievales, que apuntan a un público femenino más activo en el ámbito de la recepción literaria respecto a los hombres. Sobre este asunto véanse también Chevalier (1976: 65-103), Lucía Megías (2002), Maillard Álvarez (2005), Marín Pina (2011:351-375), Ruiz García (2005) y Borsari (2012).

3. Los estudios sobre las distintas clases y funciones de los personajes femeninos de los libros de caballerías tienen una bibliografía rica y brillante; para señalar algunos de los más sobresalientes, mencionamos a Beltrán (2009), Haro Cortés (1998), Lucía Megías y Sales Dasí (2005), Marín Pina (1989, 1991, 2007, 2010) y Mérida Jiménez (1994, 1998). 
en el marco de una expresión humorística que posibilita enfrentarse a un tema potencialmente transgresor de forma más inocua y despreocupada.

Las damas de compañía aparecen frecuentemente como consejeras y confidentes; pueden formar parte del séquito de un caballero, aunque se caractericen prioritariamente por su relación de cercanía y confianza con una doncella ${ }^{4}$. Se trata de figuras gracias a las cuales la relación amorosa mantiene uno de sus rasgos fundamentales, es decir, que se guarde en secreto, condición propia del amor cortesano recomendada por Andrés el Capellán en el De amore: «qui suum igitur cupit amorem diu retinere illaesum, eum sibi maxime praecavere oportet, ut amor extra suos terminos nemini propaletur, sed omnibus reservetur occultus $\gg$ (II, 1:288).

Merece la pena mencionar, en esta categoría, el personaje de Darioleta, compañera de Helisena en el Amadís de Gaula, que actúa como intermediaria con el rey Perión y la asiste durante el embarazo y el parto ; en el Amadís caben en esta categoría también Mabilia y la doncella de Dinamarca, compañeras de Oriana. En el Tristán de Leonís se encuentra la figura de Brangel, doncella de Iseo la Brunda, en el Florisel de Niquea (IV parte, libro II) Sarpentarea es amiga y confidente de Arquisidea, así como Lardenia acompaña a Diana en su relación amorosa. En el Palmerín se puede mencionar al personaje de Brionela ${ }^{6}$, a la que Polinarda, a los trece años, confiesa su amor hacia el héroe protagonista, y en el Primaleón Artada, consejera de Flérida en temas sentimentales, en concreto sus amores con Duardos; además, curiosamente, Artada es hija de Brionela, así que parece haber heredado su papel de consejera de la madre ${ }^{7}$. Brionela está unida a Polinarda, su prima, por un sincero vínculo de afecto fraternal y se caracteriza por ser «sesuda y mesurada» (Palmerín: 72), rasgos frecuentemente asociados con esta categoría de personajes: Artada también es «sesuda» (Primaleón: 221, 227), así como Mabilia se define «muy sabida»y «muy cuerda» (Amadís: $380,480)$. Algunas de estas figuras femeninas suelen protagonizar su propio enredo amoroso secundario, paralelo al de los personajes principales, según un esquema estructural de paralelismos reiterado también en el teatro del Siglo de Oro; Brionela, por ejemplo, en cuanto prima y amiga de Polinarda, se enamora y se casa con Tolomé, primo y amigo del mismo Palmerín.

Estas doncellas se identifican como «amigas» de las protagonistas femeninas, que se dirigen a ellas precisamente con este apelativo (véanse, por ejemplo, Amadís: 234, 752, 1223; Palmerín: 72, 79, 81, 109, 203; Primaleón: 226), declarando explícitamente confiar en ellas («yo vos amo tanto que ninguna cosa vos puedo encobrir de mi coraçón», Palmerín: 81). Suelen facilitar la comunicación entre amantes (por ejemplo, entregando cartas amorosas, como hace Brangel para Iseo y Tristán, en el cap. 37 del Tristán de Leonís) y, para hacerlo, se relacionan con frecuencia con los enanos, intermediarios amorosos a los que recurren los caballeros, como es el caso de Urbanil, escudero de Palmerín, al que Brionela pide noticias sobre su amo por parte de Polinarda, solicitando también su colaboración para concertar citas secretas entre los dos enamorados (Palmerín: 35, 72, 98). También ayudan a las jóvenes enamoradas a la hora de buscar oportunidades para acercarse a su amado, dejando que los dos se hablen durante encuentros nocturnos clandestinos a través de

4. Haro Cortés (1998: 196) define a este personaje precisamente como «doncella o dueña criada fiel».

5. Darioleta representa el modelo más reconocible de esta clase de personajes, hasta el punto de que se ha convertido en Francia en una figura proverbial, cuyo nombre identifica precisamente a una confidente o dama de compañía (Baret, 1970: 174).

6. Paralelamente, también Agriola tiene una «doncella», Femia, que como Brionela pertenece a la nobleza, siendo hija del duque de Norgales (mientras Brionela es hija del duque de Sansoña).

7. La joven le dirá a Flérida, animándola a confiarle sus secretos y congojas: «¿Por qué vos encubrís vós de mí sabiendo que yo moriría de grado por vuestro servicio? ¿Y qué cosa puede ser ésta tan grande que vós no me digáis? ¿Y no sabéis vós que mi madre, la Duquesa, fue secreto y coraçón de vuestra madre? ¿YY pues qué menos faré yo a vos que soy su fija?» (Primaleón: 226). 
las rejas de la ventana de su habitación (Amadís, I: 56; Palmerín, cap. 35; Primaleón, cap. 110) ${ }^{8}$ o en huertas y jardines (Platir, caps. 29, 39). Además, ofrecen consuelo para las preocupaciones o las angustias de las doncellas, por ejemplo, por la lejanía del amado (Primaleón, caps. 127, 146), o por la convicción de que el amado ha fallecido (Amadís, cap. 20). Tienen un papel central en solucionar conflictos que podrían perjudicar el desenlace amoroso feliz, y así, por ejemplo, Sarpentarea en la Cuarta parte de Florisel de Niquea anima a Arquisidea para que se entregue sin reservas a sus sentimientos hacia Rogel, dejando de preocuparse del bienestar de sus vasallos antes que del propio (II, cap. 10). Las doncellas acompañan también a las amigas en momentos importantes de su vida sentimental y familiar: en la mayoría de los casos están presentes en el mismo momento en el que brota el sentimiento de la protagonista, que luego confía a la amiga sus impresiones (Palmerín, cap. 31; Primaleón, cap. 98); Brionela es testigo del matrimonio entre Polinarda y Palmerín, al que sigue su mismo casamiento con Tolomé, según el mencionado esquema de imitación”; Mabilia, por otra parte, asiste a Oriana durante el parto (Amadís, cap. II, 66).

Además de posibilitar el desarrollo del enredo amoroso principal a través de encuentros clandestinos y comunicaciones secretas, las doncellas confidentes también facilitan los encuentros eróticos entre los protagonistas ${ }^{10}$. Esto ocurre, por ejemplo, en el caso de Brionela, que ayuda a Polinarda y Palmerín para que puedan verse después de la promesa de matrimonio para consumar su amor. La intervención puede incluso convertirse en una participación directa y física, con la doncella que expresa su total fidelidad con el sacrificio de su propia virginidad, como es el caso de Brangel, que llega a sustituir a Iseo en su cama durante su noche de boda con el rey de Mares, para evitar que este descubra que la doncella ya no es virgen (Tristán de Leonís, cap. 26).

En algunos casos, estas figuras femeninas desempeñan también un papel de educadora sentimental, incluso por lo que atañe a comportamientos eróticos. Un ejemplo se encuentra con la figura de Artada: durante un encuentro secreto entre Duardos y Flérida, un descuido de Artada le permite a Duardos hacer dueña a Flérida contra su voluntad (Primaleón, cap. 123); ante el llanto y la angustia de Flérida por lo ocurrido, Artada le expone con claridad por qué este comportamiento del caballero queda justificado:

8. En el caso del Palmerín, es interesante notar otros rasgos de paralelismos entre la pareja principal y la secundaria: durante una cita nocturna entre Polinarda y Palmerín, Briolana encuentra a Tolomè, hablando con él a través de otra ventana. A pesar de que Briolana desempeñe el papel de consejera, es ella misma la que acaba usando la relación entre Polinarda y Palmerín como modelo de comportamiento para su ligazón amorosa con Tolomé, decidiendo que, «pues Polinarda e Palmerín se amavan, [...] lo que ellos fiziessen farín ellos» (83); y efectivamente, cuando los dos caballeros tienen que partir para una aventura, Polinarda y Palmerín se despiden con otra conversación nocturna a la ventana, «e ansí fizieron Tolomé y Brionela» (88).

9. Polinarda en esta circunstancia parece ser consciente del comportamiento imitativo de Brionela y expresa su preocupación por ser responsable también de su matrimonio al no tener la licencia del emperador para casarse: «Amiga Brionela, ¿cómo no tuvistes más seso que yo? Que no quisiera que sin licencia del Emperador tomárades marido, porque no me cargaran dos culpas» (Palmerín: 109).

10. Entre los consejos que Ovidio en el Ars amatoria ofrece al amante es trabar amistad con la criada de la doncella que quiere seducir, para que le facilite la conquista (Beltrán, 1989: 95). Sobre la figura y función del mensajero amoroso véase también El collar de la paloma: «es necesario elegirlo, entresacarlo, probarlo y buscarlo con el mayor cuidado, pues ha de ser un indicio del entendimiento de quien lo envía y en sus manos han de estar su vida o su muerte, su ocultación o su afrenta, después de estar en las manos de Dios Altísimo. Conviene que el mensajero tenga disposición e ingenio; que entienda la menor seña, barrunte lo escondido, acierte en sus iniciativas, supla de su propia minerva lo que se le escapa al que lo envía, transmita a éste cuanto vea en el rostro del amado; que sea, en fin, discreto, cumplidor de los compromisos, leal, poco exigente y buen consejero. Si de tales cualidades carece, perjudica al que lo envía en la misma medida en que le faltan [...]. Las personas más empleadas por los amantes para comunicarse con los que aman son, o bien criados en quien nadie para mientes y que no despiertan recelos, por su poca edad, por lo desastrado de su porte o por la zafiedad pintada en su rostro, o bien, por el contrario, personas respetables y fuera de toda sospecha, por la piedad que aparentan o por la avanzada edad a que han llegado. ¡Cuántas hay así entre las mujeres!» (Hazm, 1985: 144-145). 
si vos tenéis por muy cierta de avello por marido, ¿qué vos pena aver fecho por él lo que fazistes la ora que vós tuvistes coraçón de salir a fablar con él encubiertamente y le dexastes llegar a vós de cualquiera manera que fuesse? Que por fuerça él avía de tomar aquella parte de vós que dessava (Primaleón: 297).

La violencia, potencialmente incontrolada, impulsada por sentimientos eróticos, queda sometida a las reglas del juego amoroso de las relaciones cortesanas y normalizada por ellas, cuyo funcionamiento es aclarado por parte de figuras femeninas como las de Artada a aquellas doncellas que no tengan experiencia en el ámbito amoroso o erótico. Se trata de una función central, que Artada comparte, como veremos, con otras doncellas confidentes: la violación representa un momento de tensión entre la pareja y de ruptura de los equilibrios; la perspectiva de la doncella suele ser la de víctima, hasta la intervención de la amiga confidente, que se encarga de persuadir a la doncella para que acepte esta agresión masculina como parte del juego amoroso, expresión inevitable del deseo del caballero y, según las palabras de la misma Artada, consecuencia natural del comportamiento de Flérida, que se había mostrado predispuesta a aceptar el cortejo de Duardos.

La violación y la consecuente resistencia femenina como elemento intrínseco a la relación erótica tiene origen clásico y se explicita ya en el Ars amatoria de Ovidio ${ }^{11}$, para luego trasmitirse a la literatura amorosa y erótica de los Siglos de Oro, integrándose en la tradicional concepción misógina de la mujer como ser mentiroso y llegando a formar parte de un código cultural establecido ${ }^{12}$.

Plaerdemavida, la doncella de Carmesina en el Tirant lo Blanch, es sin duda una de las figuras femeninas más atrevidas que se puedan identificar en el género caballeresco; doncella de gran desparpajo y malicia, indiscreta, testigo de encuentros nocturnos entre amantes a los que brinda su ayuda. La doncella, entonces, desempeña en la novela este papel tanto en relación con Carmesina, su ama, como con Tirant, según la que podríamos calificar como una «pedagogía del placer», cuyo objetivo final es la consumación del acto sexual. En la perspectiva de Plaerdemavida lo más importante de la relación sentimental es el goce y el placer, y lo que dificulta o impide alcanzar la satisfacción del deseo se supera con engaños y trampas burlescas; las convenciones sociales, así como las pertenecientes al código cortesano, se aplican y tienen valor en la medida en que se puedan interpretar para alcanzar esta satisfacción sexual.

En primer lugar, intenta convencer a Tirant para que supere sus vacilaciones y adopte hacia su amada la misma actitud que tendría que manifestar en batalla, tomándola por la fuerza ${ }^{13}$ :

jamés en batalla sereu ardit ni temut si en amar dona o donzella una poqueta de força no y mesclau, majorment com no u volen fer. Puix teniu sperança bona e gentil e amau donze-

11. Véase por ejemplo los versos I, vv. 673-676: «Vim licet appelles, grata est vis ista puellis: / quod iuvat, invitae saepe dedisse volunt. / Quaecumque est Veneris subita violata rapina, / gaudet et improbitas muneris instar habet» (Ovidio, 2005: 398).

12. En el ámbito de la poesía erótica, merece la pena mencionar el Jardín de Venus por las numerosas referencias a la resistencia femenina ante la violación, representada como un juego erótico: «Primero es abrazalla y retozalla, / y con besos un rato entretenella. / Primero es provocalla y encendella, / después luchar con ella y derriballa» (Alzieu [et al.], 1983: 11; núm. 5, vv. 1-4); «Aquel cogerla a oscuras a la dama / y echarla, luego, mano a la camisa, / y aquel su resistir y mucha risa» (1983: 25; núm. 15, vv. 1-3); «Aquel llegar de presto y abrazalla, aquel ponerse a fuerzas él y ella, aquel cruzar sus piernas con las della, y aquel poder él más y derriballa» (24, vv. 1-4, p. 35); «iQué alegres son al triste enamorado / las iras de su dama con blandura!» (1983: 41; núm. 26, vv. 1-2).

13. Beltran (1983: 131 ss.) se dedica al estudio de la metáfora del encuentro sexual entre los amantes como lucha en el Tirant, estableciendo un paralelismo estructural entre el desarrollo de la acción del enredo militar y el de la acción amorosa en el marco de la obra. Sobre el tema de la violación y de sus implicaciones sociales y jurídicas, véase Bazán Díaz (2003); para una perspectiva que incluye también el derecho canónico se señala Brundage (2000: 212-214; 258-259; 298-299; 372-373; 450-451; 511-513). 
lla valent, anau a la sua cambra e gitau-vos en lo lit, com ella hi sia nua o en camisa, e feriu valentment (cap. 229: 887).

De hecho, las recomendaciones de la doncella sobre la conducta sexual de los amantes no se apartan de los consejos sexuales para mujeres casadas que se incluyen también en la poesía erótica del Siglo de Oro, por ejemplo, en el Jardín de Venus, donde se explicita cómo el ejercicio de la fuerza es el único posible desenlace satisfactorio para el hombre:

Siempre habéis de mostrar que sois forzadas,

Que os vence el marido, y con reparos

De resistencia siempre habéis de armaros,

Y veréis cómo sois más estimadas.

(Alzieu, 1983: 30; núm. 19, vv. 5-8)

Mujer, aunque sintáis lo que yo quiero,

De agora para siempre os amonesto

Que no os pongáis a punto tan de presto,

Ni luego me metáis por el sendero.

Dejádmele buscar a mí primero;

Haced como que vos no dais en esto;

Haced que como a hombre que es molesto

Me deis entrada con semblante fiero.

Si vos de mí sois luego sujetada,

Piérdese la mitad de todo el gusto;

No sabe mucho lo que poco cuesta ${ }^{14}$.

(Alzieu, 1983: 31; núm. 20, vv. 1-11)

Sin embargo, en el caso de Plaerdemavida, estas mismas recomendaciones se dirigen a Tirant, que parece oponerse a la idea de la violación de su amada por razones sociales, consciente de la superioridad social de Carmesina, hija de los emperadores de Grecia. La joven doncella, sin embargo, está revelando al caballero que la violación como acción erótico-jocosa no es satisfactoria solo para el hombre, sino también para la mujer, que se espera esta actitud por parte del hombre y participa en el juego con la escenificación de su resistencia: «tot lo que diu la nóvia és manlevat, car les paraules que diu no hixen de l'ànima» (Martorell, 2008: 862; cap. 220), dirá Plaerdemavida explicando esta retórica de la violación ${ }^{15}$. Precisamente como hace Artada, Plaerdemavida ilustra, en este caso al caballero, las reglas del juego del cortejo amoroso y erótico, en el que la fuerza, hasta llegar a la violación, se configura como un comportamiento no solo admisible, sino también deseable.

En concreto, el obstáculo principal para la unión de los dos enamorados del Tirant lo Blanch no es la vacilación de Tirant, sino la oposición de Carmesina, que, precisamente como las dudas del caballero, brota de razones sociales y morales. La unión carnal con Tirant, de hecho, se opone a la educación de la princesa, que por lo tanto se ofrece solo después haber conseguido una promesa matrimonial por parte de su amado. La educación tradicional de las mujeres, representada

14. Parece evidente la referencia a Ovidio: «quod datur ex facili, longum male nutrit amorem: / miscenda est laetis rara repulsa iocis» (Ars amatoria, III, vv. 197-580; Ovidio, 2005: 482).

15. El episodio de la violación de Melibea en la Celestina (auto XIV) representa una obra maestra en la representación de la tensión entre consentimiento y rechazo que fundamenta esta retórica. 
por Carmesina, contrasta con la perspectiva naturalista que la doncella intenta enseñar a la pareja: Plaerdemavida anima a la joven para que supere su reticencia y no se atenga a las normas sociales, ya que su prioridad tendría que ser mantener vivo el amor de su caballero. Eso es lo que afirma por ejemplo respecto al beso: «si a vós volien besar, ho deuríeu consentir, e encara si us posaven les mans davall les faldes en aquest temps de gran necessitat» (631; cap. 146). El erotismo se configura, entonces, como una herramienta para alimentar el interés masculino o, como ella misma dice: «conservar la amistat dels cavallers» (ibid.). La misma resistencia de la mujer durante el encuentro erótico pertenece a esta lógica de espectacularización de la relación sexual -en la cual encaja también el vocabulario de la conquista militar-, según la cual la mujer actúa con el papel que le compete en el ámbito de un código cultural compartido, en el que esta forma de aparente rechazo tiene una función determinada, la de aumentar el placer del encuentro erótico y, a la vez, incrementar su valor para ambos. La unión entre Carmesina y Tirant es un perfecto ejemplo de la realización final de las enseñanzas de Plaerdemavida y de esta interpretación lúdica de la relación sexual, según la cual el «falso defenderse» (Alzieu, 1983: 42; núm. 26, v. 9) de la dama se interpreta como juego erótico que alimenta el deseo masculino:

no vullau usar de vostra bel.licosa força, que les forces de una delicada donzella no són per a resistir a tal cavaller. [...] Los combats de amor no.s volen molt strényer. No ab força, mas ab ginyosos afalachs e dolços engans se atenyen. Dexau porfídia, senyor, no siau cruel. No penseu açò ésser camp ni liça de infels. No vullau vençre la qu.és vençuda de vostra benvolença. Cavaller vos mostrareu damunt la abandonada donzella ? Feu-me part de la vostra homenia perquè us puga resistir. Ay senyor! Y com vos pot delitar cosa forçada? Ay! E amor vos pot consentir que façau mal a la cosa amada? Senyor, deteniu-vos, per vostra virtut e acostumada noblea. Guardau, mesquina, que no deuen tallar les armes de amor, no han de rompre, no deu nafrar la enamorada lança! Hajau pietat, hajau compassió de aquesta sola donzella! Ay cruel, fals cavaller! Cridaré! Guardau, que vull cridar! Senyor Tirant, ¿no haureu mercé de mi? No sou Tirant. Trista de mi! ¿Açò és lo que yo tant desijava? O sperança de la mia vida, vet la tua princessa morta! (Martorell, 2008: 1418; cap. 436).

Es importante notar que los preceptos eróticos y amorosos que Plaerdemavida quiere transmitir a Carmesina y Tirant, aunque contrasten con la imagen tradicional que la moral común -y sobre todo cristiana - atribuye a la mujer, encajan en la lógica del amor cortés, explicitando la connotación erótica del cortejo usual. Andrés el Capellán también, por ejemplo, avisa que «retinetur quoque amor delectabilia et suavia carnis exercendo solatia, talia tamen et tanta quae tediosa non videantur amanti. Sed quoscunque actus vel corporis gestus amotor suae cognoverit ese placabiles coamanti, eos pulchre et viriliter studeat exercere» (De amore, II, $1 ; 1985: 290)^{16}$.

La fuerza cómica del personaje procede precisamente de la función de explicitar sin vergüenza ni reticencia este aspecto de la relación amorosa, que en la mayoría de los casos quedaba mencionada a través de alusiones y omisiones en la literatura caballeresca. El objetivo principal de Plaerdemavida, en cambio, es facilitar el desarrollo del aspecto erótico de la relación entre Carmesina y Tirant, llegando incluso a medidas extremas y engañosas, introduciendo a Tirant en la cama de Carmesina sin el consentimiento de la joven. Y cuando la princesa se da cuenta de lo que está

16. De hecho, la doncella le debe a su amado una forma de recompensa por su servicio caballeresco, que puede expresarse también en alguna manifestación erótica. Sobre las varias etapas que pueden formar parte del ritual del amor cortés véase el clásico trabajo de Riquer (1975: I, 90). 
ocurriendo, le tapa la boca para que no grite, amenazándola con la posibilidad de un escándalo social: «callau, senyora, e no vullau difamar la vostra persona. He gran dubte que no ho senta la senyora emperadriu» [madre de Carmesina] (904; cap. 233). La enseñanza de Plaerdemavida se sigue centrando en la aceptación de la violencia y de la voluntad masculina; y la princesa cede a la seducción de Tirant, decidiendo que la deshonra privada es el mal menor respecto a la deshonra pública ${ }^{17}$. Este desdén hacia la honra y hacia las convenciones sociales que reglamentaban el comportamiento femenino es uno de los rasgos que aparta Plaerdemavida de las demás amigas confidentes: la joven consigue el acercamiento erótico entre los enamorados, aprovechando aquellas mismas normas sociales y morales por las cuales Carmesina no quiere ofrecerse al caballero. Plaerdemavida se coloca, entonces, en el polo opuesto respecto a aquellas damas de compañía que se encargan de proteger la honestidad de sus amas o de restaurar su honor frente a la pérdida de la virginidad antes del matrimonio. Darioleta es el perfecto prototipo de esta conducta en su función de intermediaria entre Helisena y el rey Perión. Darioleta parece atrapada en un dilema moral donde se enfrentan, por una parte, la fidelidad a su amiga y el deseo de ayudarla y, por otra parte, la conciencia de que esto conlleva una transgresión que va a afectar la honestidad de la misma Helisena ${ }^{18}$. La obediencia y el cariño hacia la amiga ganan este conflicto interior y Darioleta concierta, tras la petición de Helisena, una cita clandestina con Perión ${ }^{19}$ :

señora, bien veo yo que, según la demasiada passión que aquel tirano amor en vos ha puesto, que no ha dexado de vuestro juizio lugar donde consejo ni razón aposentados ser puedan, y por esto siguiendo yo no a lo que a vuestro servicio devo, mas a la voluntad y obediencia, haré aquello que mandáis por la vía más honesta que mi poca discreción y mucha gana de os servir fallar pudieren (Amadís: 232).

Aun secundando los deseos de la amiga, Darioleta se muestra sabia y prudente, exigiendo previamente del rey la promesa de que aceptará a Elisena como su mujer. La característica principal de Darioleta es la discreción, como se precisa reiterando la justificación por este encuentro erótico: «si no fuera por la discreción de aquella donzella suya, que su honra con el matrimonio repa-

17. Este concepto queda perfectamente explicado en las palabras de la Viuda Reposada cuando comenta la reacción de Carmesina a la declaración amorosa de Tirant, reprochándole su actitud abierta hacia el caballero: «Digau-me, senyora, ¿és justa cosa ni honesta que la vostra altesa faça tanta festa com feu a un servidor de vostre pare [...]? : E per tal home com aquest voleu perde la perpetual fama de vostra honesta pudicícia, no podent viure en àbit de donzella ni com a filla de emperador, de la qual persecució e infàmia en serien leses les orelles dels hoints? Deixau la honestat a part posada e gloriejau-vos del que deuríeu abominar, la qual cosa tota donzella se deu lunyar de tals inconvenients qui porten ab si vergonya [...]. E més vos valria morir o no ésser exida del ventre de vostra mare que tal infàmia vingués a notícia de les gents de honor. E si us ajustau ab ell per amor no lícita, què diran de vós?» (Martorell, 2008: 526527; cap. 127).

18. En el Amadís Mabilia comparte esta actitud, es decir el deseo de asistir a la amiga y protegerla de las transgresiones. En el caso de Mabilia, por ejemplo, la joven expresa su preocupación por cómo las acciones de Oriana pueden afectar la relación con sus padres, intentando recordarle que «según vuestra salud dessean, toda cosa que vos agradare farán» (753).

19. La situación presenta un parentesco con un episodio del Tristán de Leonís el Joven, donde la camarera Zafira acepta ayudar a Trinea, amazona enamorada de Tristán, a acercarse a su amado; sin embargo, en este caso, Zafira no consigue obtener el consentimiento del caballero para un encuentro nocturno. Esto no desanima a Zafira, que hace entrar a Trinea durante la noche en los aposentos de Tristán que, pese a sus resistencias, se deja seducir por la belleza de la joven (caps. 166-169). Zafira, de hecho, parece no concebir su función como la de una consejera («Señora, avéisme atajado, pues no tengo de hablar en daros consejo» [686], sino su intención es la de hacer que la voluntad de Trinea se cumpla («señora, holgad y aved plazer, que yo vos daré la presa en las manos a toda vuestra voluntad» [690]), sin revelarle que Tristán no ha consentido a este encuentro y aún a costa de actuar contra la voluntad del caballero, («estos amores se efectuaron contra la voluntad del rey» [699]). 
rar quiso, en verdad ella de todo punto era determinada de caer en la peor y más baxa parte de su deshonra» (240). Helisena se presenta, por tanto, como exemplum de conducta potencialmente negativa, a la cual pone remedio la sensatez de Darioleta. Consecuentemente, es solo después de la resolución de este conflicto moral cuando, en la perspectiva de la dama de compañía, el encuentro erótico puede convertirse en una ocasión de goce ${ }^{20}$.

Es evidente que las convenciones morales y, sobre todo, sociales de Darioleta representan un polo opuesto respecto a la perspectiva más sensorial y naturalista de Plaerdemavida, que se aparta de las normas sociales establecidas y tradicionalmente registradas en la literatura caballeresca; cuando Tirant le propone a Plaerdemavida casarse con el señor de Agramunt, la actitud de la joven en cuestiones amorosas se expresa, finalmente, en una magistral declaración que sintetiza el sentido de sus acciones y de lo que ha intentado enseñar a Carmesina y Tirant: «fogiu de mi, castedat, honesta vergonya e temerosos pensaments» (1308; cap. 382). La castidad y la vergüenza en particular aparecen frecuentemente como principios que las doncellas tienen que seguir y aplicar en su vida, pilares de su misma educación: «si en la mujer no hubiese de haber más de una virtud forzosa, esta habría de ser la vergüenza», afirma Pedro de Luxán en sus Coloquios matrimoniales $(21-22)^{21}$, así como Vives mantiene que «la castidad es la virtud más importante para ella [la doncella] y es la única que tiene el valor de todas las demás» (De institutione, X, 1: 119).

La connotación cómica del papel de Plaerdemavida procede, por una parte, de sus declaraciones atrevidas y acciones engañosas, que contrastan con su supuesta joven edad, así como de su voluntad de incluirse a sí misma en la relación sexual de los dos amantes: la tradicional función de intermediaria amorosa se convierte en la de intermediaria erótica. En el cap. 231, le permite a Tirant entrar en el dormitorio de la princesa mientras esta se está bañando, poniendo especial atención para que el caballero consiga verla desnuda. Desde este lugar privilegiado, el caballero contempla la belleza de Carmesina, mientras Plaerdemivida toma, de hecho, el lugar de Tirant, desempeñando el papel del amante, reproduciendo sus gestos mientras habla con él, proponiéndose como vehículo intermediario del encuentro sexual entre los dos. Tirant goza de este momento de voyerismo, imaginándose en el lugar de la joven, que parece de esta forma acompañar con una demostración física sus enseñanzas eróticas:

Mira, senyor Tirant, vet ací los cabells de la senyora princessa: yo.ls bese en nom de tu [...] Vet ací los hulls, e la boca: yo la bese per tu. Vet ací les sues cristal.lines mamelles, que tinch cascuna en sa mà: bese-les per tu. Mira com són poquetes, dures, blanques e lises. Mira, Tirant: vet ací lo seu ventre, les cuxes e lo secret (Martorell, 2008: 895-897; cap. 231).

No faltan otras ocasiones en las que esta actitud de Plaerdemavida como intermediaria se manifiesta como puro protagonismo y su intervención para favorecer el desarrollo de la relación sexual entre los protagonistas parece convertirse en afán de alimentar su propio voyerismo y sus

20. Esta vertiente de la relación erótica queda expresada por la descripción anterior al mismo encuentro de Helisena con Perión: «Darioleta se levantó y tomó a Helisena assí desnuda como en su lecho estava, solamente la camisa y cubierta de un manto, y salieron ambas a la huerta [...] y abriéndole el manto, católe el cuerpo y dixo riendo: - Señora, en buena hora nasció el cavallero que os esta noche avrá» (Amadís: 237)

21. En el Florisel (IV, libro II) también se afirma que la enseñanza principal que hay que trasmitirle a una doncella es «aver verguença» (fol. $83 \mathrm{v}$ ). 
perversiones. Otro episodio significativo en este sentido es el de las $\ll$ bodas sordas ${ }^{22}$, durante el cual está presente como testigo a dos encuentros eróticos que ocurren simultáneamente en la misma habitación, por la sencilla razón que «tenia desig de veure e sentir tot lo fet» (703; cap. 162).

Plaerdemavida representa una figura atípica entre las damas de compañía, una relectura burlesca del personaje centrada en una función puramente erótica. En este sentido, es evidente el parentesco con la figura de Brangel, así como el espíritu diferente con el que las dos realizan la misma acción: Brangel sustituye a Iseo en su encuentro erótico con el rey con la intención de protegerla, dando una ulterior prueba de su fidelidad a través de este sacrificio; Plaerdemavida, en cambio, sustituye a Tirante creando, por una parte, una ocasión para acercar a los dos enamorados y, por otra parte, una situación de la que ella misma puede gozar. Si las acciones de Brangel se interpretan como un sacrificio motivado por su afición a la amiga, Plaerdemavida quiere sacar de la situación erótica su propia satisfacción y diversión, jugando con la pareja y facilitando, a la vez, la relación entre los dos enamorados.

El personaje de Plaerdemavida, precisamente por su papel de educadora erótica, comparte varios rasgos con la figura femenina celestinesca, de tradición medieval, la de la vieja alcahueta que con sus artes y engaños posibilita encuentros amorosos de jóvenes doncellas para gozar, de forma indirecta, de sus aventuras eróticas. Una definición caracterizadora de estas figuras se encuentra en el Espéculo de los legos, donde se explicita su naturaleza demoniaca: «la alcahueta es mouedora a luxuria [...]. Ay algunas mugeres que quando veen que no pueden seruir ellas al diablo en aqueste pecado por la grand vejez, dan sus armas a las fijas [...] porque con las tales armas siruan las fijas a Satanás» (1951:360-361). Plaerdemavida representa, así, un personaje ambiguo precisamente por caracterizarse por rasgos aparentemente opuestos, que renueva elementos típicos -en muchos casos humorísticos- de la misoginia medieval, pertenecientes a un código bajo y protagonizado por personajes humildes, en un contexto cortesano y caballeresco. El resultado es mostrar una figura femenina moderna e innovadora, prototipo de una mujer sensual, despojada de todas las superestructuras sociales, culturales y religiosas, que abraza su naturaleza sin rémoras, animando a la amiga Carmesina para que haga los mismo y aprenda a sacar provecho del juego amoroso. Como se mencionaba, Plaerdemavida no descuida las normas del código del amor cortesano, sino que interpreta este lenguaje de forma aprovechada, aceptando lo que corresponde con su deseo de diversión y rechazando las limitaciones relacionadas con las convenciones matrimoniales. Ya ha sido estudiado el personaje de la doncella lasciva en los libros de caballerías, que se caracteriza por actuar puramente para satisfacer sus deseos sexuales, al contrario de lo que ocurre usualmente con las doncellas protagonistas, que consideran la consumación sexual como culminación del proceso amoroso ${ }^{23}$. Plaerdemavida representa, también en la expresión del deseo erótico, un caso de ambigüedad, ya que su satisfacción sexual depende de la satisfacción sexual de los demás, en concreto de Carmesina, a la que acompaña y asiste en este proceso de educación sentimental y

\footnotetext{
22. Beltrán (1990) estudió el episodio a la luz de una comparación con la Celestina, donde, en los autos VII, XIV y XIX, se produce una situación estructuralmente análoga entre Pármeno y Areúsa, por una parte, y Calisto y Melibea por la otra.

23. Lucía Megías y Sales Desí (2005) identifican en el marco de la categoría de doncellas lascivas varios prototipos diferentes, como el hada amante, o maga lasciva (Urganda del Amadís de Gaula, Malfada del Palmerín de Olivia, Blanca Flor del Arderique, Laciva del Floriseo; Aguilar Perdomo [2004: 21] enumera entre estas figuras también Argónida del Primaleón y Parvia del Platir), o las doncellas con las que caballeros seductores establecen breves relaciones adúlteras, como ocurre en la tercera parte del Florisel de Niquea con personajes como la reina de Galdapa o Ganta, así como con Florecinta en el Clarisel de las Flores, jóvenes lascivas y hermosas, señoras de castillos y seductoras, libres del control paterno. Otras clasificaciones de personajes femeninos, con correspondientes ejemplos, fueron proporcionadas por Haro Cortés (1998) y por Aguilar Perdomo (2004).
} 
erótica que es perverso e ideal a la vez, puesto que su última consecuencia es el triunfo del amor entre Carmesina y Tirant.

Un personaje distinto de los mencionados, pero digno de nota por su función y por su actitud irónico-burlesca en el marco de la educación sentimental, es Triola, en el Platir. Triola se enamora y es correspondida por Vernao, quien la salva de las atenciones indeseables de un caballero; esta relación con Vernao, emperador de Alemania y compañero de Platir, le permite entrar en la corte y establecer una relación de amistad con Florinda, enamorada del mismo Platir, de la que se hace confidente y maestra en los dilemas amorosos que la joven no sabe cómo enfrentar sola. La relación entre las dos mujeres es fuente de varias conversaciones de las que emerge un espíritu humorístico y jocoso, que juega con las diferentes actitudes de las dos: la evidente falta de experiencia amorosa de Florinda la lleva a reacciones impulsivas cuyas potenciales consecuencias la misma Triola intenta contener.

Triola quiere enseñar a Florinda a evitar los celos cuando la joven descubre en el brazo de otra doncella, Silbia, una perilla que reconoce ser un don que ella misma había anteriormente entregado a Platir, creyendo, por eso, haber sido engañada por el caballero: «así me á burlado en dar lo que yo le avía dado con sus puras importunaciones» (Platir: 161). Triola intenta hacer razonar a la amiga y apaciguar sus dudas sobre los sentimientos de su amado ( $\ll$ no creáis que el infante Platir vos olvidasse por donzella del mundo» [161]), pero, a pesar de esto, Florinda envía precipitadamente a Platir una carta para romper su relación amorosa. Triola censura duramente el comportamiento de Florinda, considerándolo desmesurado respecto a lo acaecido, y afirmando que «procede todo esto del poco amor que le tenedes» (164). El papel de Triola, entonces, convencida la joven de lo grave de su error, será no tanto de posibilitar el carteo entre los dos, sino, al contrario, de interceptar la carta antes que llegue a las manos de Platir. La actitud de Triola, a pesar de ser severa, acaba siendo más apacible, ya que acompaña sus duras palabras a Florinda ( «me partiré con Vernao [...] para darvos descanso; y no tanto por vos [...], que no lo merecéis cierto, como por el infante, que sé yo que está bien inocente d'este pecado» [164]) con una sonrisa. De hecho, esta actitud censora pero, al mismo tiempo, afable y benigna, incluso en sus expresiones jocosas, siempre caracteriza el comportamiento de la mujer con la amiga.

Triola, de hecho, ya se ha familiarizado con el carácter celoso de Florinda; el mismo amor de la joven nace y se manifiesta asociado con estos celos al ver a Platir acompañado precisamente por Triola en ocasión de un torneo. A pesar de las aclaraciones de Triola sobre la falta de cualquier vínculo amoroso que la una a Platir, Florinda no consigue superar sus preocupaciones y sigue tratando de averiguar cosas sobre Triola y su presencia al lado del caballero. La primera conversación entre las dos doncellas ya evidencia la falta de experiencia amorosa de la joven Florinda que $\ll$ no sabía que responder. Como donzella nueva en aquel menester, estava fuera de seso» (135). A partir de este momento nace la amistad entre las dos doncellas, cuando Triola consigue conquistar la confianza de Florinda, animándola a «descubrir todo lo que encubierto tenía en su coraçón» $(136)^{24}$.

Triola desempeña el papel tradicional de la dama de compañía confidente, actuando como intermediaria entre los enamorados, apaciguando los celos de Florinda e incluso permitiendo a los dos de desarrollar su relación: los supuestos amores de Platir con Triola, de la que el caballero

24. A pesar de esto, los celos de Florinda quedan solo aparentemente aplacados, ya que «aún no estava ella muy segura de la grande sospecha que d'ella [Triola] y del infante Platir tenía» (Platir: 138); solo la llegada a corte de una doncella que ofrece la posibilidad de una nueva aventura le permitirá resolver sus dudas, poniendo a prueba nuevamente el amor de Platir para estudiar sus reacciones en presencia de la misma Triola y de esta nueva doncella. 
finge ser servidor, favorecen y encubren sus relaciones con Florinda y le permiten acercarse a la joven, por ejemplo, en ocasión de un torneo (cap. 29). Sin embargo, la afición de Triola hacia Florinda no le impide burlarse de ella: la naturaleza socarrona y provocadora de Triola se manifiesta precisamente como reelaboración posterior del comportamiento de Florinda, puesto que la doncella se mofa de la actitud sospechosa y desconfiada de la amiga. En el cap. 50, Florinda reconoce la devoción de Platir, admitiendo de forma implícita haberse equivocado en sus pasadas evaluaciones sobre su infidelidad («conozco que no estoy engañada con él» [230]). Triola le recuerda, bromeando, sus fallos pasados, por los cuales no merecería la consideración del caballero:

- ¿Nos vos dixe yo muchas vezes que no podría faltar el infante Platir y Vernao que no nos
viniesse a ver? [...].
- Cierto, yo lo tuve bien ansíi, dixo Florinda, «que siempre en los tiempos que yo más
ncessidad tove me socorrió a mí el infante. En esto conozco que no estoy engañada con él.
- En otras muchas cosas lo devríades vós, señora, conoscer, -riéndose- si toviéssedes
buen conocimiento para con él, mas sois una burladora y escarnís de Platir a vanderas
desplegadas. Yo vos certifico que si él me creyesse, que se tornase tanto que me viesse a
mí y dexase a Vernao conmigo.
- ¡Ay por Dios - decía Florinda contra Triola- no me digades esso, que aun burlando no
lo querría oír tanto me pena! -decía Florinda (Platir: 230).

Triola manifiesta una constante postura crítica por la actitud de Florinda hacia Platir, siempre hablando en defensa del caballero y de su honestidad en respuesta a las manifestaciones de celos y dudas por parte de la doncella, que siguen emergiendo durante varias aventuras ${ }^{25}$. Triola, de hecho, conoce a Platir antes que a Florinda, y se convierte en primer lugar en su confidente, acompañándolo durante parte de sus hazañas caballerescas. Solo gracias a su complicidad es posible orquestar el encuentro nocturno durante el cual Florinda pierde la virginidad y su propósito principal es precisamente que Platir consiga satisfacer sus deseos: «cuidava ella que todos aquellos desmayos eran con sobra de amor causados y que ternían aquel fin que el infante tantos tiempos avía desseado» (184). No hace falta ningún engaño ni ningún descuido por parte de Triola, sino que los deja voluntariamente solos para que se cumpla el deseo de Platir, aunque contra la voluntad de Florinda; y contrariamente a la empática reacción de Artada, al descubrir lo ocurrido, enfrentándose con el enojo de Florinda, Triola:

culpó mucho a Florinda diziéndole que ante le avía de tener en servicio la voluntad con que aquello le avía dicho, pues todo se hacía por más su honra tener en aquel grado y cuenta que ella merecía y ponerla en aquel descanso que ella desseava. Muchas cosas decía la donzella Triola a la infanta, trayéndole a la memoria cuántos cavalleros sacaron princesas y reinas de sus propios señoríos y se casaron con ellas y las tenían en aquella veneración que su estado requería tenerse. [...] Tanto predicó la donzella Triola a la infanta hasta que la fizo algo assossegar y los fizo entrar en los grandes palacios, do fueron echados en un lecho la infanta Florinda y Platir, y ansí estovieron ya muy amigos no aviendo memoria de aquellos enojos (Platir: 186).

25. Véase también el cap. 39: «grande es el amor quél infante vos tiene, señora - dezía Triola-. No gelo pagáis cierto vomo devríades y él lo merece, que dudo aya oy día cavallero en el mundo que se le iguale en cosa ninguna» (Platir: 182). 
La actitud burlesca y provocadora de Triola se vuelve a manifestar después del nacimiento del hijo de la pareja, cuando escucha una conversación privada entre Platir y Florinda, durante la cual acaba burlándose de las palabras formales que los dos intercambian, preguntándole a Platir: «si por caso es ésta la vez primera que le habla [a Florinda] que tantos ofrecimientos le haze. Mucha cierto es la desenvoltura de la donzella si es ésta la vista primera» (237). Se juega aquí con una desacomodación entre los registros lingüísticos empleados que aparta a Triola de su función tradicional, para volver a hacer referencia a unas normas lógicas y naturales de comportamiento amoroso que nada tienen que ver con el código cortesano. La perspectiva naturalista de Triola se opone, por tanto, a las convenciones del amor cortés a las que se refiere Platir y del que se burla la doncella «en manera de desdén, riéndose de lo que tan afincadamente decía el uno al otro» (237), destacando un desajuste entre lo que el código cortesano requiere y la natural interacción entre amantes que comparten cierta intimidad. Platir parece aceptar el juego de la doncella, contestándole con el mismo espíritu humorístico; tras una respuesta convencional sobre el natural crecimiento del amor y antes de despedirse, abraza y besa a su amada, pidiendo burlescamente la aprobación de Triola: «allí decía Platir a Triola si cabrán bien los ofrecimientos que él hazía a la infanta $\gg$ (p. 238). Florinda, por otra parte, reacciona manifestando otra vez su inexperiencia y su incapacidad a la hora de participar en el juego amoroso con el mismo tono burlesco proporcionado por Triola: en primer lugar, se ríe y se esconde ( «se metió debaxo de la ropa y se abraçó con el infante» (Platir: 237) y, sucesivamente, ruega a Triola que pare sus provocaciones ( $\ll$ no digades esso, que burlando ni de veras no lo quiero oír $\gg ; \ll$ no me digades esso [...]. Por lo que más amáis y preciáis en este mundo vos lo pido» [237-238]), provocando con su ingenuidad la risa de Triola («grande fue la risa que Triola tomó de ver cuán de veras tomava esto que le decía burlando la infanta Florinda» [238]).

El desconocimiento -o quizás simulado desconocimiento- de Triola de ciertas convenciones amorosas se ha notado también en su aproximación al carácter celoso de Florinda. Los celos se configuran tradicionalmente como un rasgo intrínseco del amor cortés, una reacción natural que tiene que producirse en presencia de un amor auténtico ${ }^{26}:$ «sine xelotypia verum amorem non posse consistere» (De amore, I, 6: 192). En este sentido la actitud sospechosa de Florinda es perfectamente admisible y no condenable, expresión de su pasión y etapa natural del amor que posibilita su propio crecimiento, como ocurre con todas las dificultades que los amantes tienen que superar; se declara explícitamente en el Platir al afirmar que superar los celos que Florinda le tenía a Triola por su relación con Platir «fue causa de crecer más en su amor como cresció hasta la muerte» (Platir: 136).

Por lo general, los reproches de Triola educan a Florinda no tanto al conocimiento del código amoroso cortesano, como a aproximarse a este código con un espíritu jocoso. Los celos, así como la resistencia frente a la fuerza del hombre en el encuentro erótico, crean entre los enamorados una tensión que forma parte de situaciones codificadas que representan obstáculos para los amantes y que es menester superar, sobre todo por parte de la doncella, que tiene que desarrollar cierta destreza en este juego amoroso.

26. Véase el ejemplo de Oriana en el Amadís, analizado por Cacho Blecua (2010) a la luz de la ira y del comportamiento descontrolado provocado por los celos. Merece la pena señalar que, en cambio, los manuales de educación femenina de la época suelen considerar los celos femeninos como un sentimiento negativo y maligno. Vives, por ejemplo, admite los celos solo después del casamiento y solo por parte del marido (De institutione, libro II, cap. VIII, 3: 272), así como Luján en los Coloquios matrimoniales recomienda moderar los arranques de celos, también por parte de los hombres («alabo y tengo por bueno ser los hombres con sus mujeres cautelosos, mas desalabo y repruebo ser celosos» [98]), así como hace también Fernando de Riojas en el Florisel (IV, libro II: fol. 85v). 
Este papel desempeñado por Triola se acomoda a la descripción de su personalidad, definida como «muy graciosa [...] y muy gran dezidora» (230) y «muy del palacio y dezidora sobre manera, tanto que nunca estaban sino riendo doquiera que ella estava» $(132)^{27}$. Se trata de una cualidad que Pedro de Luján asocia con las mujeres de manera especialmente negativa, criticando las que hacen donaires, cuentan fábulas y «cuentos feos y llenos de gazafatones»; asimismo observa que «muchas mujeres presumen de ser decidoras, graciosas y mofadoras» y que «lo que en los hombres llamamos gracia, en las mujeres llamamos chocarrería» (Coloquios matrimoniales: 22). Esta característica se opone, de hecho, a una de las cualidades que los moralistas de la época apuntan como entre las más deseables para una mujer, es decir, ser callada: «la mujer honesta y grave no se ha de preciar de donosa y decidora, sino de honesta y callada» (Coloquios matrimoniales: 22), perspectiva compartida también por Vives.

Sin embargo, existe también otro modelo femenino del que algunos humanistas elogian la actitud, sobre todo en relación con el entorno cortesano y con la capacidad de establecer relaciones sociales brillantes y manejar con sabiduría y elegancia el arte de la conversación. Así, en el Florisel de Niquea (IV, libro II) no se critican las mujeres graciosas en absoluto, sino que se matiza esta tajante afirmación manteniendo que hay que enseñarles que «las burlas y donaires [...] sean templadas, que no causen deshonestidad con demasiada desemboltura» (fol. 84r). De hecho, este modelo de mujer y dama de compañía que atiende a las princesas es, en muchos casos, una mujer que pertenece a la nobleza, como en el caso de Triola, Brionela y Artada, y que, por lo tanto, tiene que saber expresarse en el contexto de la corte. La imagen tradicional femenina como perteneciente a la esfera doméstica y privada, en consecuencia, se entrelaza con las exigencias de la vida de corte $y$, si por una parte se multiplican los manuales sobre el comportamiento de la perfecta esposa, por otra parte algunos humanistas representan a una figura de mujer más implicada en la sociedad cortesana, como ocurre en el caso del Cortegiano de Castiglione, que incluye también un manual del arte de la conversación y de la vida de palacio, en el ámbito del cual la mujer necesita disponer de otras capacidades:

27. «Dezidor/decidor» parece ser un término con acepción ambigua; por lo general se refiere a «la persona que sabe hablar bien y dice gracias» (Autoridades). En este sentido, puede tener también valor negativo, como le atribuye el Pinciano al hablar de «dicacidad y murmuración y fealdad y torpeza de palabras» (Philosophía antigua poética, IX: 395), en contraposición con las palabras humorísticas «urbanas y discretas» (ibid.), asociando con el vocablo una connotación negativa que no tenía en su significado original latino (dicacitas) empleado por Cicerón. Según Roncero López (2006: 319), se trataría de un matiz moralizante añadido por el Pinciano, que «dota a [la risa] de un aspecto negativo, amoral». La dicacidad queda vinculada con la murmuración también en el Corbacho en dos ocasiones: «detractor embidioso e murmurador, el maldecidor -cuchillo de dos tajos, que alaba en presençia e denuesta en absençia» (164), y, pocas líneas después, «el mucho fablador e escarnidor, mofador e de otros dezidor, murmurador e burlador» (ibid.). Una definición bien conseguida de la ambigüedad del término la proporciona Cristóbal de Villalón: «al mordaz murmurador que con sus chocarrerías y donaires injuria a todos llaman buen dezidor y hombre de buena conversación» (Scholastico: 44); sin embargo, al describir a un estudiante de nombre Durango el término parece asumir un valor más positivo: «el más artero y mas sagaz [...]; era gran dezidor, tocava con muy graçiosa industria a todos con sus donaires y motes, y hazía a sus amigos muchos pasatiempos de plazer» (Scholastico: 21). En el ámbito picaresco «dezidor» parece asociarse con un significado positivo, como ocurre en la Segunda Celestina de Feliciano de Silva («hombre con razonable gesto, gracioso, y dezidor y desembuelto» (419). El término parece aplicarse al hombre cortesano y a su arte de conversación que, de forma análoga, puede resultar en expresiones de hipocresía y falsedad y, al mismo tiempo, brotar de astucia y del manejo inteligente del arte de la conversación, acepción con la cual se emplea asimismo en el Libro del cavallero Zifar («era mucho apuesto en sy, e de muy buen donario e de muy buena palabra e de buen resçebir, e jugador de tablas e de axadres, e muy buen caçador de toda aue mejor que otro ome, dezidor de buenos retrayres, de guisa que quando yua camino todos auian sabor de le aconpañar por oyr lo que dezia» [354]). 
Lassando adunque [...] quelle condizioni che si convengono a tutte le donne, come l'esser bona e discreta, il saper governar le facultà del marito e la casa sua e i figlioli quando è maritata, e tutte quelle parti che si richieggono ad una bona madre di famiglia, dico che a quella che vive in corte parmi convenirsi sopra ogni altra cosa una certa affabilità piacevole, per la quale sappia gentilmente intertenere ogni sorte d'omo con ragionamenti grati ed onesti, e accomodati al tempo e luogo e alla qualità di quella persona con cui parlerà. [...] Non deve adunque questa donna, per volersi far estimare buona e onesta, essere tanto ritrosa e mostrare tanto di aborrire e le compagnie e i ragionamenti ancor un poco lascivi, che ritrovandovisi se ne levi; perché facilmente si poria pensare ch'ella fingesse di essere tanto austera per nascondere di sé quello ch'ella dubitasse che altri potesse risapere. [...] Non deve tampoco, per mostrare di essere libera e piacevole, dire parola disoneste, né usare una certa domestichezza intemperata e senza freno e modi da far credere di sé quello che forse non è, ma ritrovandosi a tali ragionamenti, deve ascoltarli con un poco di rossore e vergogna (III, 5: 348-350).

Un prototipo de mujer entendida, por tanto, que se aparta de la imagen de la mujer «callada», ya que, con argucia y discreción, puede debatir sobre cualquier tema.

De hecho, el género caballeresco, gracias a su enorme difusión, supuso una fuente de distintos modelos de comportamiento, incluso femeninos, y consecuentemente también un medio de transmisión de preceptos didácticos ${ }^{28}$, a pesar del reproche generalizado de los moralistas hacia estas obras $^{29}$. La esfera amorosa no puede quedarse fuera de este propósito, sobre todo al considerar la amplitud del público de lectoras femeninas. Por un lado, la representación literaria de los vínculos amorosos comparte varios rasgos con la realidad de las relaciones matrimoniales, bajo el punto de vista del aspecto jurídico y familiar, así como en la indudable conciencia de la necesidad de una tutela masculina para las mujeres ${ }^{30}$; sin embargo, por otro lado, la lógica literaria del amor cortés también se aparta de la realidad social en otros aspectos y en concreto representa al hombre como servidor de su amada, rasgo que, precisamente vista la condición de sumisión social y familiar de la mujer, podemos imaginar que pudo haber ejercido una atracción especial para las lectoras. En este sentido, entonces, personajes como Triola y Plaerdemavida se presentan como figuras que enseñan a sus amigas esta capacidad de prender al hombre y someterlo a su voluntad a

28. Véase Martín Romero (2004-2005) sobre el propósito didáctico que se declara explícitamente en algunos textos caballerescos, no solo a través de la representación de distintos modelos de comportamiento, sino también con la inserción de glosas moralizantes o parlamentos didácticos impartidos por algunos personajes, en un sistema en el que se inscriben también elementos simbólicos y alegóricos; Gutiérrez Trápaga (2013) identifica en algunas novelas caballerescas la intención explícita del autor de orientar la lectura hacia una función didáctica a partir de los paratextos. Los libros de caballerías ofrecen también retratos de figuras ejemplares y, así, por ejemplo Duce García (2016) estudia el Valerián de Hungría como prototipo de la perfecta educación del príncipe, formado en estudios humanísticos, además que experto en el arte militar, según recomiendan los tratados de la época; análogamente, también algunas figuras clásicas quedan reinterpretadas para proporcionar ejemplos de conducta deseables o reprochables, como en el caso del personaje de Medea estudiado por Campos García Rojas (2011). Martín Romero (2007) recuerda que varios autores de libros de caballerías compusieron también tratados didácticos.

29. Sobre este tema véase Sarmati (1996) para una perspectiva general; Gagliardi (2010: 34 y ss.) se dedica también a un análisis de lo que se consideraban los peligros que la lectura indiscriminada de literatura de entretenimiento supuestamente conllevaba para las mujeres, reconocidas como el público más vulnerable.

30. Para una perspectiva general del aspecto jurídico del matrimonio en la época véase Martín (2001), Pérez Molina (1994) y los trabajos reunidos en el volumen La condición de la mujer en la Edad Media, en particular Beceiro Pita (1986), Pérez-Prendes y Muñoz de Arraco (1986), Pastor de Togneri (1986) y Segura Graíno (1986). 
través del poder del erotismo y de la seducción, interpretado bajo un punto de vista jocoso, aunque en registros muy diferentes.

Estos dos modelos de figuras femeninas proporcionan una forma nueva de incluir el elemento erótico en el ámbito de la literatura más elevada, sin omisiones ni reticencias, sino de forma más explícita; el humorismo representa el instrumento lingüístico y narrativo a través del cual es posible conseguirlo, pero de una forma innovadora: la lujuria de las mujeres se expresa como recurso cómico al ser usualmente ridiculizada y, por consiguiente, gravemente reprochada. Los personajes que acabamos de examinar, en cambio, representan el erotismo como una fuerza positiva, transgresora sin ser repulsiva ni despreciable, enseñando a otras doncellas a aceptar este aspecto de la esfera amorosa, aclarando su legitimidad en el contexto del amor cortesano. De hecho, al contrario de lo que ocurre con algunas figuras femeninas que se dedican a la seducción, como por ejemplo las mujeres lujuriosas ancianas, no acaban siendo ridiculizadas ni humilladas, no son centro de bromas ni marginadas o escarnecidas; en resumidas cuentas, no son objeto pasivo, sino más bien motor activo de risa. La misma función de estos personajes contrasta evidentemente con lo que se recomendaba para las amigas y damas de compañía de una doncella de alta alcurnia: «salga de casa acompañada de la madre, si la tiene y si es posible, pero si no tiene, hágalo en compañía de una mujer respetable, viuda, casada o incluso doncella de vida honesta, que tenga una conversación casta y sobria y está adornada con un pudor respetable» (De institutione, XI, 2: 133-134) ${ }^{31}$. $\mathrm{Y}$, efectivamente, la educación sentimental al amor cortés proporcionada de manera humorística por estas figuras femeninas se coloca en evidente antítesis respecto a los numerosos tratados de los humanistas cristianos de la época, que se dedican al tema de la educación femenina y a la formación de la mujer para el matrimonio. En estas obras la adquisición de las virtudes necesarias para llegar al compromiso matrimonial pasa por la negación de la pasión ${ }^{32}$, elemento perjudicial y disociado del amor matrimonial consagrado, mientras que la educación al amor cortés es precisamente educación a la pasión, que también se presenta como un conocimiento necesario para llegar al matrimonio.

Los tratados de educación femenina suelen presentar el amor como una fuerza tremenda, un «peligroso veneno que nos priva de nuestros ojos y nos arrastra y nos conduce, una vez cegados, por mil principios y abismos» (De institutione, XIII, 2; Vives, 1994: 158), obstruyendo la parte más sensata y racional, ya que ejerce su predominio «de forma algo desordenada y confusa en nuestra mente, para alterarla todo a su capricho y antojo» (ibid.). En cambio, personajes como Artada, Triola o Plaerdemavida proporcionan un punto de vista alternativo, es decir una forma

31. Son varias las obras que ven la luz en esta época y que reflexionan sobre el papel social de la mujer, relacionado con la familia, la devoción conyugal y la educación de los hijos. Propio de la mujer es el universo privado, nunca público, hasta el punto de que también el salir de casa tiene normas muy rígidamente establecidas, sobre todo para limitar el contacto con hombres: «conviene siempre mantener el mínimo trato posible con los varones; hay que intercambiar con ellos muy pocas palabras y estas tienen que estar impregnadas de modestia, castidad y prudencia» (De institutione, XI, 4; Vives, 1994: 140). Se suma a esta tendencia también Feliciano de Silva, quien, consciente de las críticas de los moralistas al género caballeresco incluye en el Florisel de Niquea (IV, libro II) unas explícitas intervenciones didácticas sobre la honestidad de las mujeres y sobre la educación de las doncellas: los caps. 43 y 45 se dedican a un diálogo entre damas que, aunque surja en un contexto de risa y diversión, se propone con tono serio, casi oficial, puesto que queda redactado por una de las doncellas con la intención de ordenar algunas reflexiones e, incluso, con la elección de un título: «ornamentos de princesas». Otro diálogo sobre el mismo tema ocurre en el cap. 72, cuando algunas damas debaten sobre el comportamiento de Lucrecia, su suicidio y su relación con Tarquino. Martín Romero (2004-2005; 2007) ha estudiado estos aspectos didácticos destinados a las mujeres.

32. «La castidad es la virtud más importante para ella [la doncella] y es la única que tiene el valor de todas las demás» (De institutione, X, 1; Vives, 1994: 119). 
racional para aprender a gestionar los sentimientos y las reacciones que los acompañan, como si formaran parte de un juego amoroso con reglas claras que hay que aprender para ganar el premio final; el resultado final parece apuntar a la creación, a través de este recorrido caballeresco, de un manual práctico de comportamiento amoroso cortesano que se inscribe en una forma de didacticismo que se puede formular solo a través del humorismo, puesto que representa un punto de vista transgresor respecto a la perspectiva tradicional, tanto social como cristiana.

\section{Bibliografía}

Aguilar Perdomo, María del Rosario (2004), «Las doncellas seductoras y requeridoras de amor en los libros de caballerías españoles», Voz y letra, 15, 1, pp. 3-24.

Alzieu, Pierre; Robert Jammes y Yvan Lissorgues (1983), Poesía erótica del Siglo de Oro, Barcelona, Crítica.

BARET, Eugène (1970), De l'«Amadís de Gaula», et de son influence sur les moeurs et sur la littérature au XVI et au XVII siècle: avec une notice bibliographique, Ginebra, Slatkine Reprints, 1970.

BAzÁN DÍAz, Iñaki (2003), «El estupro. Sexualidad delictiva en la Baja Edad Meida y primera Edad Moderna», Mélanges de la Casa de Velázquez, 33, 1, pp. 13-46.

Beceiro Pita, Isabel (1986), «La mujer noble en la Baja Edad Media castellana», en La condición de la mujer en la Edad Media (Actas del Coloquio celebrado en la Casa de Velázquez, del 5 al 7 de noviembre de 1984), eds. Yves-René Fonquerne y Alfonso Esteban, Madrid, Editorial de la Universidad Complutense, pp. 289-313.

Beltrán, Rafael (1983), Tirant lo Blanc: evolució i revolta en la novel.la de cavalleries, Valencia, Institució Alfons el Magnànim.

(1989), «Eliseu (Tirant lo Blanc) a l'espill de Lucrecia (la Celestina): retrat de la donzella com a còmplice fidel de l'amor secret», en Miscel.lània Joan Fuster, ed. Antoni Ferrando y Albert G. Hauf, Barcelona, Abadía de Monserrat, vol. I, pp. 95-124.

(1990), «Las «bodas sordas» en Tirant lo Blanc y La Celestina», Revista de Filología Española, 70, pp. 91-117.

(2009), «Cinco mujeres activas en el Tirant lo Blanc: contra el estereotipo de la sumision amorosa en el libro de caballerías», en Amadís y sus libros: 500 años, eds. Aurelio González y Axayacatl Campos Garcia Rojas, México D.F., El Colegio de México, pp. 241-276.

BorsARI, Elisa (2012), «Los libros de caballerías en la corte de los Gonzaga, señores de Mantua: la biblioteca de Isabela de Este y Federico II $\gg$, en De cavaleiros e cavalarias. Por terra de Europa e Américas, ed. Lênia Márcia Mongelli, Sâo Paulo, Humanitas, pp. 191-204.

BRundage, James. A. (2000), La ley, el sexo y la sociedad cristiana en la Europa medieval, México D.F., Fondo de Cultura Económica.

CACho Blecua, Juan Manuel (2010), «La saña en el Amadís de Gaula (II): la ira del rey y los celos de Oriana», en «De ninguna cosa es alegre posesión sin compañía»: estudios celestinescos y medievales en honor del profesor Joseph Thomas Snow, ed. Devid Paolini, Nueva York, Hispanic Seminary of Medieval Studies, vol. II, pp. 45-65.

CAmpos García Rojas, Axayácatl (2011), «Medea en los libros de caballerías hispánicos: libros, mito y ejemplaridad», Acta poética, 32, 2, pp. 115-143.

[EL] CAPELlán, Andrés (1985), De amore. Tratado sobre el amor, ed. Inés Creixell Vidal-Quadras, Barcelona, Quaderns Crema. 
Castiglione, Baldassarre (1981), Il libro del cortegiano, ed. Bruno Maier, Torino, UTET.

Cervantes, Miguel de (2015), Don Quijote de la Mancha, ed. Francisco Rico, Madrid, Real Academia Española.

Chevalier, Maxime (1976), Lectura y lectores en la España de los siglos XVI y XVII, Madrid, Turner.

Diccionario de Autoridades (1726-1739), Real Academia Española, tomos I-VI. http://web. frl.es/DA.html.

Duce García, Jesús (2016), «Nacimiento y educación del héroe: el ejemplo del Valerián de Hungría $\gg$, Historias Fingidas, 4, pp. 97-119.

[EL] ESPÉCUlo de los legos (1951), ed. José M. ${ }^{a}$ Mohedano Hernández, Madrid, CSIC.

GAGLIARDI, Donatella (2010), Urdiendo ficciones. Beatriz Bernal, autora de caballerías en la España del XVI, Zaragoza, Prensas Universitarias de Zaragoza.

Gutiérrez Trápaga, Daniel (2013), «Los libros de caballerías como obras didácticas según dos prólogos artúricos: Baladro del sabio Merlín y Tristán de Leonís», Memorabilia, 15, pp. 119146.

Haro Cortés, Marta (1998), «La mujer en la aventura caballeresca: dueñas y doncellas en el Amadís de Gaula», en Literatura de caballerías y orígenes de la novela, ed. Rafael Beltrán, Valencia, Universitat de València, pp. 181-218.

Hazm de Córdoba, Ibn (1985), El collar de la paloma, ed. Emilio García Gómez, Madrid, Alianza.

Huizinga, Johan (2010), El otoño de la Edad Media: estudios sobre la forma de la vida y del espíritu durante los siglos XIV y XV en Francia y en los Países Bajos, Madrid, Alianza.

Libro del Caballero Zifar (2001), ed. Cristina González, Madrid, Cátedra.

López Pinciano, Alonso (1998), Philosophía Antigua Poética, ed. José Rico Verdú, Madrid, Fundación José Antonio de Castro.

Lucía Megías, José Manuel (2002), «Libros de caballerías castellanos: textos y contextos», Edad de Oro, 21, pp. 9-60.

y Emilio José SALes Dasí (2005), «La otra realidad social en los libros de caballerías (II).

Damas y doncellas lascivas», en Actes del X Congrés Internacional de l'Associació Hispànica de Literatura Medieval (Alacant, 16-20 de setembre de 2003), eds. Josep Lluís Martos Sánchez, Josep Miquel Manzanaro i Blasco y Rafael Alemany Ferrer, Valencia, Institut Interuniversitari de Filologia Valenciana, vol. II, pp. 1007-1022.

Luxán, Pedro de (1943), Coloquios matrimoniales, Madrid, Atlas.

Maillard Álvarez, Natalia (2005), «Lecturas femeninas en el Renacimiento: mujeres y libros en Sevilla durante la segunda mitad del siglo XVI», en Mujer y cultura escrita: Del mito al siglo XXI, coord. María del Val González de la Peña, Gijón, Trea, pp. 167-182.

Marín Pina, M. ${ }^{a}$ Carmen (1989), «La aproximación al tema de la virgo bellatrix en los libros de caballerías españoles $\gg$, Criticón, 45, pp. 81-94.

(1991), «La mujer y los libros de caballerías. Notas para el estudio de la recepción del género caballeresco entre el público femenino», Revista de literatura medieval, 3, pp. 129-148.

(2007), «La doncella andante en los libros de caballerías españoles: antecedentes y delimitación del tipo (I)», en Actas del XI Congreso Internacional de la Asociación Hispánica de Literatura Medieval (Universidad de León, 20 al 24 de septiembre de 2005), eds. Armando López Castro y María Luzdivina Cuesta Torre, León, Universidad de León, vol. II, pp. 817-825. 
(2010), «La doncella andante en los libros de caballerías españoles: antecedentes y delimitación del tipo (II) $\gg$, eHumanista, 16, pp. 221-239.

(2011), Páginas de sueños. Estudios sobre los libros de caballerías castellanos. Zaragoza, Institución Fernando el Católico.

MARTín, José Luis (2001), «El proceso de institucionalización del modelo matrimonial cristiano», en La familia en la Edad Media. XI semana de estudios medievales (Nájera 2000), coord. José Ignacio de la Iglesia Duarte, Logroño, Instituto de Estudios Riojanos, pp. 151-178.

Martín Romero, José Julio (2004-2005), «"Buenas dotrinas y exemplos”. Aspectos sapienciales y didácticos en los libros de caballerías $\gg$, Memorabilia, 8 [http://parnaseo.uv.es/Memorabilia/memorabilia8/martin/index.htm]

(2007), «El "Ornamento de princesas": un diálogo sobre educación femenina de Feliciano de Silva», Tirant, 10, s.p.

[http://parnaseo.uv.es/Tirant/Butlleti.10/Art.Romero_Feliciano.htm].

Martínez de Toledo, Alfonso (1981), Arcipreste de Talavera o Corbacho, ed. Michael Gerli, Madrid, Cátedra.

Martorell, Joanot (Martí Joan De Galba) (2008), Tirant lo Blanch, ed. Albert Hauf, Valencia, Tirant lo Blanch.

MÉRIDA JimÉNEZ, Rafael (1994), «Elogio y vituperio de la mujer medieval: hada, hechicera y puta», en Actas del IX Simposio de la Sociedad Española de Literatura General y Comparada (Zaragoza, 18 al 21 de noviembre de 1992), Zaragoza, Universidad de Zaragoza, vol. I, pp. 269-276. (1998), «La imagen de la mujer en la literatura castellana medieval: hacia un laberinto bibliográfico de mudable fortuna (1986-1996)», Acta Historica et Archaeologica Mediaevalia, 19, pp. 403-431.

Ovidio Nasón, Publio (2005), Ars amatoria, en Obras completas, ed. Antonio Ramírez de Verger, Madrid, Espasa Calpe, pp. 359-497.Ovidi

Palmerín de Olivia (2004), ed. Giuseppe di Stefano, Alcalá de Henares, Centro de Estudios Cervantinos.

PAstor De Togneri, Reyna (1986), «Para una historia social de la mujer hispano-medieval: problemática y puntos de vista», en La condición de la mujer en la Edad Media (Actas del Coloquio celebrado en la Casa de Velázquez, del 5 al 7 de noviembre de 1984), eds. Yves-René Fonquerne y Alfonso Esteban, Madrid, Editorial de la Universidad Complutense, pp. 187-214.

PÉRez Molina, Isabel (1994), «Las mujeres y el matrimonio en el derecho catalán moderno», en Las mujeres en el antiguo régimen. Imagen y realidad (ss. XVI-XVIII), Barcelona, Icaria, pp. 21-56.

Pérez-Prendes y Muñoz de Arraco, José Manuel (1986), «La mujer ante el derecho público medieval castellano-leonés: génesis de un criterio», en La condición de la mujer en la Edad Media (Actas del Coloquio celebrado en la Casa de Velázquez, del 5 al 7 de noviembre de 1984), eds. Yves-René Fonquerne y Alfonso Esteban, Madrid, Editorial de la Universidad Complutense, pp. 97-106.

PlatiR (1997), ed. Marín Pina, $M^{a}$ Carmen, Alcalá de Henares, Centro de Estudios Cervantinos. PRIMALEón (1998), ed. Marín Pina, $\mathrm{M}^{\mathrm{a}}$ Carmen, Alcalá de Henares, Centro de Estudios Cervantinos.

RiQuer, Martín de (1975), Los trovadores, Barcelona, Planeta.

Rodríguez de Montalvo, Garci (1991), Amadís de Gaula, ed. Juan Manuel Cacho Blecua, Madrid, Cátedra. 
Ruiz García, Elisa (2005), «El universo femenino y las letras (siglos XV-XVII)», en Mujer y cultura escrita: Del mito al siglo XXI, coord. María del Val González de la Peña, Gijón, Trea, pp. 97-115.

San Pedro, Diego de (1971), Cárcel de amor, ed. Keith Whinnom, Madrid, Castalia.

SARMATI, Elisabetta (1996), Le critiche ai libri di cavalleria nel Cinquecento spagnolo (con uno sguardo sul Seicento). Un'analisi testuale, Pisa, Giardini.

Segura Graíño, Cristina (1986), «Situación jurídica y realidad social de casadas y viudas en el medioevo hispano (Andalucía)», en La condición de la mujer en la Edad Media (Actas del Coloquio celebrado en la Casa de Velázquez, del 5 al 7 de noviembre de 1984), eds. Yves-René Fonquerne y Alfonso Esteban, Madrid, Universidad Complutense, pp. 121-133.

Silva, Feliciano de (1568), Florisel de Niquea (Cuarta Parte, libros I y II), Zaragoza, Pierres de la Floresta.

(1988), Segunda Celestina, ed. Consolación Baranda, Madrid, Cátedra.

TRISTÁN DE LEONís y el rey don Tristán el joven, su hijo (Sevilla, 1534) (1997), ed. $\mathrm{M}^{\mathrm{a}}$ Luzdivina Cuesta Torre, México D.F., Universidad Nacional Autónoma.

Villalón, Cristóbal de (1997), El scholástico, ed. José Miguel Martínez Torrejón, Barcelona, Crítica.

Vives, Juan Luis (1994), La formación de la mujer cristiana. De institutione feminae christianae, ed. Joaquín Beltrán Serra, Valencia, Ayuntamiento de Valencia. 